\title{
A Novel Chemistry E-Lab Software System for Improving Students' Interest and Familiarity with Laboratory Operations
}

\author{
Elahe Keshavarz \\ Department of Sciences, University of Farhangian, Rasht, Iran \\ Email: iyc.2011@yahoo.com
}

\begin{abstract}
This study presents the results of a new educational software system for familiarity with experimental equipments. The software was designed in an intuitive and accessible way so that students can see each relevant part of equipments and realize the differences, similarities and usage of them in various participated in the study. Influence of the educational software on students' learning was examined by the questionnaire. The results showed that the software provides a unique and engaging approach to learning function of laboratory equipments, and increases the efficiency of students' learning in laboratory.
\end{abstract}

Keywords: educational software, laboratory equipments, learning

\section{Introduction}

Science is one of the few subjects in which providing the most pedagogically area learning environment [1] that results in practical situation. Workaday, students at all grade levels take part in science address instruction involving hands on science activities [2].

Tentative sciences are based on experience and experimentation. The students can learn the knowledge the most easily in real encompassings where they can perceive the concepts and processes. To teach this kind of knowledge simulated environments such as laboratories are widely used. However, students should have to make laboratory as a safe location for skills expansion.

Virtual labs provide students to frequently carry out experiments in a safe environment during lessons. Virtual labs make a comfortable learning environment that takes into consideration the individual's characteristics $[3,4]$. These programs also provide an inexpensive, easy, safe, and arbitrary working environment [5].

The availability of laboratory equipment, facilities and matters play a biotic role in defining the scope of best laboratory practices that will ensure inception of science process skills and competence in science concepts by the learners. One main aspect of chemistry education that is of great concern is in the area of availability and effectiveness of use of specialized and relevant science equipment, facilities and instructional matters [6].

The challenges often confronted in doing practicals [7] in inadequately equipped laboratories has led teachers to separate science lessons into practical and theory classes and/or shifting practical work until the second term of the final year.

E-lab enables students to conduct experiments more flexibly and in an interactive way using multimedia. It helps them to achieve electronic practical training, skills, and tendencies [8].

Therefore, they are at least as effective as real laboratories in terms of acquainting students with experiment process [9], providing students with a safe experimental environment [10], allowing students to conduct experiments individually [11], providing users with more options in shorter time with interaction [12].

E-lab becomes an instrumentation to study and illuminate the experiments and their relation to theory so that student can understand the meaning of operating practical experiment while doing them $[8,13,14]$.

According to the mentioned above about the importance of laboratory and laboratory lessons in science education and also despite of the lack of full access to the laboratory, we have been designed a new chemistry software system for the full and complete training of the laboratory equipments for 
Chemistry Laboratory lessons. This software contains facilities and experiments in the field of chemistry also introduces equipment and facilities in the field of other sciences, such as physics.

\section{Results and Discussion}

The experimental work in laboratory has always supposed a high profile at all levels of science education. The original reasons for its important lay in the need to produce skilled technicians and teachers for research laboratories and classes [15]. One of the useful skills that can be used in educational field is diagnosis skills of science laboratory equipments.

On the other hand, in recent years the use of software has become ubiquitous in education settings [16-21]. It is well known that laboratory equipments are of significant importance in chemistry lab. However, education of laboratory equipments have generally been neglected in recent educational environments. Table 1 shows the reasons why chemistry teachers do not locate laboratory in their teaching. The software sometimes be a superior alternative, or simply a supportive learning environment to real laboratories. So for solving this problem we have been made a new chemistry software system.

Table 1. Problems encountered in chemistry courses

\begin{tabular}{ll}
\hline Reason for teachers' lack of use of the lab & Alternative \\
\hline Safety concerns & Suitable software \\
Lack of self-confidence & Suitable software \\
Lack of equipment & Suitable software \\
Time shortage & Suitable software \\
Student's lack of familiarity with the equipments & A software system (Novel system) \\
\hline
\end{tabular}

This work reports the use of a software system for introducing the laboratory equipments with the aim of using technology to assist instruction. The general idea is that students can be guided through a designed software system. Given the power of this software to present high-quality graphics, audio, and video offer an engaging tool for many students.

The software was designed in an intuitive and accessible way so that students can see each relevant part of equipments and realize the differences, similarities and usage of them in various experiments. The software can provide a safe environment for students to get accuinted with new equipments. Also, this aspect can lead to superficial learning, when students do not possess the foundational skills to work with equipments. It can be used to provide practice in the operation of equipment prior to using the actual device. The software has two sections: the first section, shows pictures of the experimental equipments for familiarity with them. The second section, presents animations that simulate the same processes done in the real lab.

For designing this software (Fig. 1) all the books of different educational level were studied. In order to enhancing the information, the references of each text were written below of them, so students can easily access to various scientific sites.

The study was carried out on the sample of 30 chemistry and 18 primary education student teachers from Farhangian University of Rasht. Influence of the educational software on students' learning was examined by the questionnaire. To determine the validity of the questionnaire, it was sent to one of the educational experts to examine the apparent proportionality of the questions to the target. Finally, after several correction, the validity of the questionnaire was confirmed.

The questionnaire assesses the quality of software and its impact on student learning in one of the options from too many to very little.

For this purpose, a portion of the software system was displayed for students for about 20 minutes. Before using the software, students may need instruction in both the content of the software and the correct operation of it. Then, that questionnaire was given to the students. After responsing to the questions, the students' answers were analyzed.

To analyze the data, eight important questions that covered all of our goals were analyzed.The frequency of the responses under four categories are expressed in table 2. 


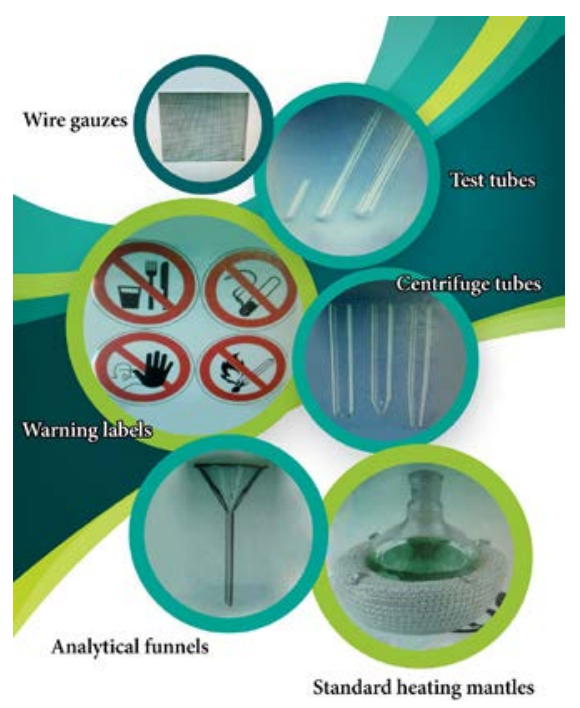

Figure 1. A computer screen image of software system

Table 2. Frequency of student response categories based on questionnaire results

\begin{tabular}{|c|c|c|c|c|c|}
\hline Number of Questions & $\begin{array}{l}\text { Very } \\
\text { little }\end{array}$ & Little & Medium & $\begin{array}{l}\text { Very } \\
\text { much }\end{array}$ & Much \\
\hline 1. I prefer to use this software Instead of going to the laboratory. & $\begin{array}{c}--- \\
---\end{array}$ & 12 & 17 & 3 & 16 \\
\hline 2. The pictures of this software are suitable and high quality. & ---- & 1 & 8 & 2 & 37 \\
\hline 3. The sounds of this software are clear and understandable. & ---- & 6 & 20 & 6 & 16 \\
\hline 4. The concepts of this software are Simple and fluent. & ---- & 1 & 14 & 7 & 26 \\
\hline 5. The introduction times of laboratory tools are suitable. & ---- & 1 & 12 & 7 & 28 \\
\hline 6. Use of this software help me to better recognize the laboratory tools. & 1 & ---- & 10 & 13 & 24 \\
\hline 7. Use of this software increses my interest in learning laboratory lessons. & ---- & 5 & 19 & 3 & 21 \\
\hline 8. I prefer to use other software for learning laboratory lessons. & ---- & 5 & 15 & 6 & 22 \\
\hline
\end{tabular}

The analysis of research questions showed that many of students believe that the quality of images and sounds of the new chemistry software is very good. Also they said that the concepts in this software are simple and fluent. All students think that this software will increase their motivation and interest in learning laboratory lessons. In fact, all students believe that this software has helped them to recognize and understanding laboratory tools and there is no difference between going to the lab and using this software.

Due to the costs of developing virtual lab environments, this software currently suffer from limited educational use, but we are working to make it available for use in schools.

\section{Conclusion}

This study examined the effects of a new chemistry software system on development of students' learning in laboratory lessons. Students in the field of chemistry and other science can use this software for studying the common equipment in physics, chemistry and other science. Science students at school or in university are not spend enough time in science laboratory so by using this software, students can reach their goal by a correct and affordable way.

The students believe that this software has a positive impact on their learning. So according to the results we can claim that by using this software the problems of many students and teachers in the field of education and training of the chemistry and other science laboratory will be substantially resolved.

Acknowledgements. The author would like to acknowledge the partial support of this work by Farhangian University. Also the author thanks 'Soode Zare' for support for the development of software. 


\section{References}

1. A. WÇİMER (2007), "Effective teaching in science: A review of literature," Turkish Science Education, vol. 4, no. $1,20-44$

2. M. C. Box, C. L. Dunnagan, L. A. S. Hirsh, C. R. Cherry, K. A. Christianson, R. J. Gibson, M. I. Wolfe and M. T. Gallardo-Williams (2017), "Qualitative and quantitative evaluation of three types of student-generated videos as instructional support in organic chemistry laboratories," Journal of Chemical Education, vol. 94, no. 2, pp. 164-170.

3. R. Guzzi, S. Scarpanti, G. Ballista and W. Di Nicolantonio (2005), "An educational development tool based on principles of formal ontology," Educational Technology \& Society, vol. 8, pp. 80-89.

4. A. K. Noor and T. M. Wasfy (2001), "Simulation of physical experiments in immersive virtual environments," Engineering Computations, vol. 18, pp. 515-538.

5. Ö. KARAGÖZ and N. ÖZDENER (2010), "Evaluation of the usability of diferent virtual lab software used in physics courses," Bulgarian Journal of Science and Education Policy, vol. 4 no. 2, pp. 216-235.

6. M. A. Katcha and D. I. Wushishi (2015), "Effects of laboratory equipment on secondary school students' performance and attitude change to biology learning in federal capital territory, Abuja, Nigeria," Journal of Education Research and Behavioral Sciences, vol. 4, no. 9, pp. 250-256.

7. J. U. Ekpo (1999), "Status of Secondary School Science Practical Work in AkwaIbom State, Nigeria" AJEIMA, vol. 2, no. 1, pp. 12-29.

8. A. Almusawi, A. Ambusaidi, S. Al-Balushi and K. Al-Balushi (2015), "Effectiveness of e-lab use in science teaching at the omani," TOJET: The Turkish Online Journal of Educational Technology, vol. 14, no. 1, pp. 4552 .

9. B. Dalgarno, A. G. Bishop, W. Adlong, and D. R. Bedgood (2009), "Effectiveness of a virtual laboratory as a preparatory resource for distance education chemistry students," Computers \& Education, vol. 53, no. 1, pp. 853-865.

10. J. D. Mercer-Chalmers, C. L. Goodfellow and G. J. Price (2004), "Using a VLE to enhance a foundation chemistry laboratory module," CAL-Laborate, vol. 12, pp. 14-18.

11. E. Bozkurt (2008), "The effects on students' success of a virtual laboratory application prepared in the physics education," Unpublished PhD thesis, Selcuk University, Konya.

12. N. Ozdener and B. Erdogan (2001), "Improving the virtual laboratories which give the possibility of evaluating the experimental data and giving feedback," Educational Science Journal of MU Faculty of Ataturk Education, vol. 14, pp. 107-120.

13. C. TÜYSÜZ (2010), "The effect of the virtual laboratory on students' achievement and attitude in chemistry," International Online Journal of Educational Sciences, vol. 2, no. 1, pp. 37-53.

14. G. M. Battle and F. H. Allen (2010), "Teavhing three-dimentional structural chemistry using crystal structure databases. 1. An interactive web-accessible teaching subset of the Cambridge structural database," Journal of Chemical Education, vol. 87, no. 8, pp. 809-812.

15. M. Ituma, N. Twoli and D. Khatete (2015), "Chemistry teachers' role in changing practical work from simple Hands On activities to more of Minds On activities," International Journal of Humanities and Social Science, vol. 5, no. 10, pp. 110-118.

16. A. AZAR and Ö. AYDIN ŞENGÜLEÇ (2011), "Computer-assisted and laboratory-assisted teaching methods in physics teaching: the effect on student physics achievement and attitude towards physics," Eurasian journal of Physics and chemistry Education, pp. 43-50.

17. H. Ndahi (2006), "The use of innovative methods to deliver technology education laboratory courses via distance learning: A strategy to increase enrollment," Journal of technology education, vol. 17, no. 2, pp. 33- 42.

18. T. Martin-Blas and A. Serrano-Fernandez (2009), "The role of new technologies in the learning process: moodle as a teaching tool in physics," Computers \& Education, vol. 52, pp. 35-44.

19. D. B. Smithrud and A. R. Pinhas (2015), "Pencil-paper learning should be combined with online homework software," Journal of Chemical Education, vol. 92, pp. 1965-1970.

20. A. E. Pierson and D. B. Clark (2018), "Engaging students in computational modeling: the role of an external audience in shaping conceptual learning, model quality, and classroom discourse," Science Education, vol. 102, no. 6, pp. 1336-1362.

21. J. L. Davenport, A. N. Rafferty and D. J. Yaron (2018), "Whether and how authentic contexts using a virtual chemistry lab support learning," Journal of Chemical Education, vol. 95, no. 8, pp. 1250-1259. 